
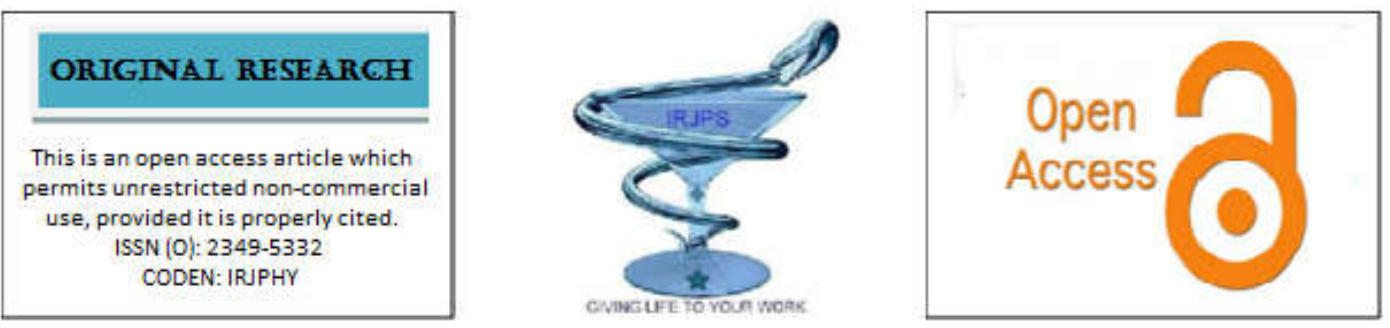

\title{
STUDY OF RATIONALITY IN PRESCRIBING PRACTICE OF NSAIDS IN OUT PATIENT HOSPITALS FROM AN URBAN AREA OF MORADABAD (UTTAR PRADESH)
}

\author{
Aditya Sharma $^{a *}$, Mayur Porwal ${ }^{\mathrm{b}}$, Akarsh Agrawal ${ }^{\mathrm{a}}$, Vaibhav Rastogi ${ }^{\mathrm{b}}$, Arvind Kumar ${ }^{\mathrm{a}}$, Najam Ali \\ Khan $^{\mathrm{a}}$ \\ ${ }^{a}$ School of Pharmaceutical Sciences, IFTM University, Moradabad-244102, Uttar Pradesh, INDIA \\ ${ }^{\mathrm{b}}$ Pharmacy Academy, IFTM University, Moradabad-244102, Uttar Pradesh, INDIA"
}

Submitted on: 30.12.19;

Revised on: 05.01.20;

Accepted on: 18.01.20

\begin{abstract}
At present, most NSAIDs (non-steroidal anti-inflammatory drugs) are engaged in regular practice to treat various types of inflammation as well as other problems. The most serious reactions of this practice are the growth of resistance and irrational drug usage which ultimately affects patient care. Present study aims to determine rational use and prescribing pattern of NSAIDs in outpatient hospitals from an urban area of Moradabad (Uttar Pradesh), India. A sum of 720 prescriptions comprising NSAIDs assessed for their dispersion as indicated by the characterization of NSAIDs and World Health Organization center markers for recommending practices and patient consideration. An average count of medicines per prescription was 4.5. An average number of NSAIDs was observed to be 1.00per prescription. The frequency of generic drug prescribing was noted to be low. The proportion of drugs adequately labeled was $61.44 \%$. Out of the 3453 drugs, 684NSAIDs were given, of which $59.21 \%$ and $40.79 \%$ utilized as mono-treatment and Fixed Dose Combinations individually. The prescriptions were containing either one or a couple of NSAIDs. Non-selective NSAIDs were most commonly prescribed than selective cyclooxygenase-2 (COX2) inhibitors. The examination indicates more utilization of conventional NSAIDs and underutilization of COX 2 inhibitors. The examination recommends that there is the huge extent of progress for endorsing in the emergency clinics.
\end{abstract}

KEYWORDS: Prescribing pattern, Non-steroidal anti-inflammatory drugs (NSAIDs), mono-therapy, fixed dose combinations, cyclooxygenase-2 (COX 2) inhibitors.

Corresponding Author:Mr. Aditya Sharma

Tel.: +918923371669

E-mail: aditya_iftm@yahoo.com
Indian Research Journal of Pharmacy and Science; 23(2019)2035-2040 Journal Home Page: https://www.irjps.in DOI: $10.21276 /$ irips.2019.6.4.6 


\section{INTRODUCTION}

Rational utilization of drugs characterized as patients get medication suitable to their clinical necessities, in portions that encounter their own individual prerequisites, for an acceptable timeframe, and at the negligible expense to them and for their community. Prescriptions contain an extraordinary significance in regards to the balanced utilization of medication identified with cost, security, and viability. Prescriptions grant the distinguishing proof of the items by its logical names. Recommending and dispensing proposed studies are perhaps the best technique to decide objective prescribing ${ }^{1}$.

One of the most generally utilized and mishandled tranquilizes all over the world is nonsteroidal anti-inflammatory drugs (NSAIDs). Pain is an unpleasant, perceptible and passionate experience related with real or potential tissue harm, or depicted as concerns such damage ${ }^{2}$.Fever and pain are generally the most early indications various inflammatory diseases. The introduction of NSAIDs was a milestone occasion to control agony and they become the most broadly utilized prescription not just for the alleviation of pain and fever, yet in addition for their calming impact ${ }^{3}$.

NSAIDs establish the biggest single group of medications utilized around the world, bringing about colossal introduction of patients to this group of medications and their related dangers. NSAIDs are one of the most endorsed classes of medications in the OPD (outpatient department). NSAIDs are generally utilized in elder patient for the treatment of pain and fever related with aggravation in rheumatoid joint inflammation and osteoarthritis, neuromuscular issue, migraine, and musculoskeletal conditions ${ }^{4,}{ }^{5}$.Musculoskeletal issue are the most incessant reason for physical handicap in developed nations. They substantially affect wellbeing and force an overwhelming monetary weight on medicinal services systems. As indicated by world Health Organization (WHO), musculoskeletal issue are the most incessant reason for incapacity in the advanced world, and the commonness of these ailments is mounting at an alarming rate. The most conspicuous purpose behind the loss of joint versatility and capacity is ceaseless or wordy agony, which prompts mental pain and disabled personal satisfaction ${ }^{6}$.

However, NSAIDs having an antiinflammatory effect, and they are associated with the serious gastrointestinal adverse effect.
Unnecessary use of NSAIDs may result genuine adverse reactions diminishing its pharmacological outcomes $^{4}$. A prescription-based investigation considered as unique techniques to survey and assess the recommending demeanor tries to screen assess and propose changes in professionals prescribing tendencies to make therapeutic consideration normal and increasingly viable. Investigation of recommending example gives data on the normal utilization of the medication as sound utilization of the medication dependent on levelheaded prescribing ${ }^{7}$.

The principle objective of this investigation was to get information with respect to the recommending attitude towards NSAIDs by the doctors from the outpatient office (OPD) of private clinical setting. In addition to the prescribing model of NSAIDs, we assessed the information for WHO core indicators in regards to prescribing practices and patient care study through rational use.

\section{MATERIAL AND METHODS}

This prospective study undertaken for 3 months (February-April) 2019 in OPD of private hospitals in the city Moradabad (Uttar Pradesh), INDIA.

Prescriptions gathered from patients who were going to OPD just because. When the meeting by doctor finished, the prescriptions were duplicated in the wake of accepting verbal assent from the patient. The data collected during the study was kept confidential and utilized only for study purpose. The prescriptions analyzed for following indicators ${ }^{8,9}$.

WHO core indicators for prescribing practices and patient care i.e. prescribing indicators:

\section{Prescribing practices:}

a) Average number of prescribed drugs per encounter $=$ Overall number of diverse drug product prescribed /Total number of prescriptions surveyed.

b) Percentage of drugs approved by their generic name $=$ (Number of drugs prescribed by generic name/ Total number of drugs prescribed) $\times 100$.

c) Percentage of encounters prescribed containing antibiotic $=$ (Number of patient encounters containing antibiotic/ Total number of encounters surveyed) $\times 100$.

d) Percentage of drug prescribed from Essential Drug List $($ EDL $)=($ Total number of drugs 
prescribed from EDL/Total number of drugs prescribed) $\times 100$.

\section{Patient care indicators.}

a) Average dispensing time $=$ Total time for dispensing drugs to a series of patients/ Total number of drugs encounters.

b) Percentage of drugs actually dispensed = (Number of drugs dispensed/Total number of drugs prescribed) $\times 100$.

c) Percentage of drugs adequately labelled = Number of packages containing information about when the drug should be taken/ Total number of drugs dispensed.

d) Patients knowledge about correct dosage = (Number of patients, who can adequately report the dosage schedule for all drugs/ total number of patients interviewed) $\times 100$.

In addition above indicators prescriptions were also analyzed for following indicators:

i. Percentage of distribution of NSAIDS according to the COX2 (cyclooxygenase-2) enzyme selectivity for inhibition.

ii. Selective Non-selective NSAID usage ratio

iii. Percentage of medications to minimize adverse effect of NSAIDs.

iv. Duration of prescription

v. Average cost per prescription.

NSAIDs classified on the basis of exercising judgment for inhibition of the 2 major isoforms of COX enzyme are as follows ${ }^{10}$.

Class 1: Non-selective COX inhibitors- diclofenac, ibuprofen, indomethacin, mefenamic acid, naproxen, Paracetamol, etodolac, lornoxicam, aceclofenac, ketoprofen.

Class 2: Selective COX 2 inhibitors - ketorolac and nimesulide.

Class 3: Selective COX2 inhibitors - etrocoxib, lumirocoxib prescription containing injection and antibiotic.

\section{RESULTS}

In the current prospective report, 720 prescription were collected during period of 3 months. In a total 720 prescription, 684 prescription enclosing NSAIDs estimated for prescribing design. The demographic profile of patients were shown in Table 1.
Table 1: Demographic characteristics

\begin{tabular}{|c|c|}
\hline $\begin{array}{c}\text { Patient characteristics } \\
\text { by Age }\end{array}$ & $\begin{array}{c}\text { No. of prescription } \\
\text { (N \%) }\end{array}$ \\
\hline $1-17$ & $153(21.25)$ \\
\hline $18-40$ & $423(58.75)$ \\
\hline $41-60$ & $117(16.25)$ \\
\hline Above 60 & $27(3.75)$ \\
\hline Total & $720(100)$ \\
\hline
\end{tabular}

Number of patient treated by using no or single drug were $0 \%$ the average count of drugs on every prescription was 4.5 . The highest count of medications per prescription was 7 whereas 2 drugs were significantly prescribed. The average number of NSAIDs was 1, per prescription. All the prescription containing brand names, the frequency of conventional recommending was extremely low. The percentage of a prescription including NSAIDs, antiulcer, antibiotic, multivitamin, and others were $19.80 \%, 16.59 \%, 23.97 \%, 09.64 \%$, $29.97 \%$ respectively. The category of drugs prescribed was shown in Table 2.

Table 2: Category of drugs prescribed

\begin{tabular}{|c|c|}
\hline Category of drugs & $\mathbf{( N ~ \% )}$ \\
\hline NSAIDs & $684(19.80)$ \\
\hline Antiulcer & $573(16.59)$ \\
\hline Multivitamin & $333(09.64)$ \\
\hline Antibiotic & $828(23.97)$ \\
\hline Others & $1035(29.97)$ \\
\hline Total & $3453(100)$ \\
\hline
\end{tabular}

The prescription contain total 3453 drugs out of which 3394 were oral and 59 were topical gels. Out of overall drugs, 684 were systemic NSAIDs which were distributed as mono therapy and fixed dose combination (FDCs). Out of 684 systemic NSAIDs, 405 (59.21) were used as mono therapy and 279 (40.79\%) were used as FDCs. The sex characteristics were presented in Table 3.

Table 3: Sex Characteristics

\begin{tabular}{|c|c|}
\hline Sex & N (\%) \\
\hline Male & $414(57.5)$ \\
\hline Female & $306(42.5)$ \\
\hline Total & $720(100)$ \\
\hline
\end{tabular}

The non-selective NSAIDs were most commonly prescribed then selective COX2 inhibitors. Non-selective NSAIDs prescribed in 
$90.78 \%$ of prescription. Selective COX2 inhibitors constitute for $9.21 \%$ respectively. Most prescribing NSAIDs were shown in Table 4.Paracetamol, Aceclofenac and Diclofenac were commonly prescribed NSAIDs respectively mefenamic acid and Nimesulide. Various clinical studies related to NSAIDs concluded that nonselective and to some extent, selective NSAIDs are majorly associated with gastrointestinal complication so to minimize their adverse effects, anti-ulcer drugs prescribed in $45 \%$ prescription. For the duration of 1-15 days. Most of prescription given for the duration of 4-7 days.

Table 4: Most prescribing NSAIDs

\begin{tabular}{|c|c|}
\hline Prescribed NSAIDs & No. of prescriptions (N \%) \\
\hline Paracetamol & $337(49.26)$ \\
\hline Aceclofenac & $119(17.39)$ \\
\hline Diclofenac & $104(15.20)$ \\
\hline Mefenamic acid & $53(07.74)$ \\
\hline Nimesulide & $49(07.16)$ \\
\hline Ibuprofen & $22(03.21)$ \\
\hline
\end{tabular}

The most commonly used anti-ulcer drugs were pantoprazole, omeprazole, and ranitidine comparison in Rabeprazole and Sucralfate from the class of receptor blocker pump inhibitors respectively which was given in Table 5 .

Table 5: Most prescribing antiulcer drugs

\begin{tabular}{|c|c|}
\hline Prescribed antiulcer drugs & No .of prescription \\
\hline Pantoprazole & $182(26.59)$ \\
\hline Omeprazole & $51(7.45)$ \\
\hline Ranitidine & $45(6.57)$ \\
\hline Rabeprazole & $16(2.33)$ \\
\hline Sucralfate & $14(2.04)$ \\
\hline
\end{tabular}

Out of 684, a total number of 30 FDCs of two NSAIDs (16.21\%) were prescribed and the maximum generally prescribed FDC was of aceclofenac and Paracetamol which was $10.21 \%$ shown in Table 6.

Table 6: FDCs of two NSAIDs

\begin{tabular}{|l|l|l|l|}
\hline $\begin{array}{l}\text { List of FDCs of two } \\
\text { NSAIDs }\end{array}$ & $\begin{array}{l}\text { Number } \\
\text { encounters (\%) }\end{array}$ & $\begin{array}{l}\text { Age } \\
\text { range }\end{array}$ & Indications \\
\hline $\begin{array}{l}\text { Aceclofenac } \\
\text { Paracetamol }\end{array}$ & $19(10.21)$ & $12-70$ & $\begin{array}{l}\text { Fever, Postoperative pain, Arthritis, } \\
\text { Musculoskeletal pain, Swelling, Joint pain, }\end{array}$ \\
\hline $\begin{array}{l}\text { Diclofenac arthritis, } \\
\text { Paracetamol }\end{array}$ & $08(4.32)$ & $18-68$ & $\begin{array}{l}\text { Fracture, Muscle pain, } \\
\text { dysmenorrhea, Toothache }\end{array}$ \\
\hline $\begin{array}{l}\text { Ibuprofen } \\
\text { Paracetamol }\end{array}$ & $03(1.62)$ & $16-70$ & Fever, Migraine, Headache. Toothache \\
\hline Total & $30(16.21)$ & & \\
\hline
\end{tabular}

Of 684 prescriptions of NSAIDs, $516(75.43 \%)$ were of NSAIDs registered in NLEM-2015 presented in Table 7. The most widely recognized NSAIDs according to NLEM was Paracetamol while aceclofenac was the most well-known
NSAIDs prescribed other than those recorded in NLEM. The remaining prescriptions, prescribed NSAIDs were not listed in NLEM such as Nimesulide shown in Table 7.

Table 7: Prescribed NSAIDs, listed or not listed in NLEM India 2015

\begin{tabular}{|c|c|c|c|c|}
\hline \multirow{2}{*}{$\begin{array}{c}\text { S. } \\
\text { No. }\end{array}$} & Prescribed NSAIDs listed in NLEM & \multicolumn{2}{|c|}{ Prescribed NSAIDs not listed in NLEM } \\
\cline { 2 - 5 } & Prescribed NSAIDs & $\begin{array}{l}\text { Number } \\
\text { encounters (\%) }\end{array}$ & Prescribed NSAIDs & $\begin{array}{l}\text { Number } \\
\text { encounters (\%) }\end{array}$ \\
\hline 1. & Paracetamol & $337(49.26)$ & Aceclofenac & $119(17.39)$ \\
\hline 2. & Diclofenac & $104(15.20)$ & Nimesulide & $49(07.16)$ \\
\hline 3. & Mefenamic acid & $53(07.74)$ & & \\
\hline 4. & Ibuprofen & $22(03.21)$ & & \\
\hline
\end{tabular}


Infective conditions were the common clinical conditions in hospitals for which NSAIDs were prescribed in high percentage $(29.67 \%)$ followed by fever $(9.79 \%)$ orthopedic pain $(8.47 \%)$ and musculo-skeletal pain $7.89 \%$ were depicted in Table 8.

Table 8: Clinical Indications

\begin{tabular}{|r|l|c|c|}
\hline S. No. & Clinical Indications & Frequency & Percentage (\%) \\
\hline 1. & Infective condition & 203 & 29.67 \\
\hline 2. & Fever & 67 & 9.79 \\
\hline 3. & Orthopedic pain & 58 & 8.47 \\
\hline 4. & Musculo-skeletal pain & 54 & 7.89 \\
\hline 5. & Headache & 36 & 5.26 \\
\hline 6. & Rheumatoid arthritis & 29 & 4.23 \\
\hline 7. & Osteoarthritis & 26 & 3.8 \\
\hline 8. & Dental surgery & 19 & 2.77 \\
\hline 9. & Severe injury & 14 & 2 \\
\hline 10. & others & 178 & 26.02 \\
\hline Total number of NSAIDs=684 & \multicolumn{2}{|l}{} \\
\hline
\end{tabular}

\section{DISCUSSION}

Prescription based survey provides the reflection of clinical judgment. Non-selective NSAIDs are the commonly used class of NSAIDs. However nonselective NSAIDs contains the higher percentage of total NSAIDs prescribed. Nimesulide, Paracetamol, Mefenamic acid and Aceclofenac were the mainly prescribed drugs along with Paracetamol. FDCs (Fixed dose combinations) offer the benefit of some pills to be taken and hence patient adherence. The research also suggested that $16.21 \%$ of prescription with combination of fixed doses. As NSAIDs related with gastrointestinal adverse effect anti-ulcers were prescribed in $42.77 \%$ of prescription. The mean calculation of drugs per prescription is a measure of polypharmacy. Polypharmacy is certainly increases adverse effect and drug interaction. The mean number of medications per prescription was observed to be 4.5. This count is very high than the WHO recommended a limit of $2^{11}$. The consideration of at least 4 or even more medications in a similar prescription was seen in $53.75 \%$ of cases. A few examinations reports no medications were recommended by generic name, which is a case of irrational prescribing. Generic medications are more financial than brand ones. Pressure from pharmaceutical organizations might be one reason for composing trade name. In Nepal $44 \%$ of drugs recommended by generic names ${ }^{10}$.Antibiotics and infusions are profoundly abused and expensive types of treatment ${ }^{12}$, however our investigation demonstrates their low to direct utilize. The utilization of infusions saw as moderate as the investigation completed in OPD of Moradabad Hospitals. The patient care indicators address the aspects of patient experiences at health care center and their information in regards to the utilization of drugs administered to them. The time prescribers and dispensers go through with every patient sets a significant farthest point on the potential nature of diagnosis and treatment. An average time is taken to dispense the drugs was seen as 1.9 minutes; this time is longer than the time observed ${ }^{12}$.Additional time is given to dispense the drugs with complete information to the patient observance to the drug.

\section{CONCLUSION}

Based on the information obtained from the present investigation, it was observed that the utilization of generally safe conventional NSAIDs coprescription of anti-ulcers and different supplements are a portion of the positive focuses in the administration pattern. Be that as it may, even now impressive scope of the improvement in the prescribing pattern, for example, underutilization of NSAIDs and over prescription of Paracetamol, aceclofenac, nimesulide, mefenamic acid was detected. Because of the limitations of the present analysis, which incorporate few prescription envisaged in a short duration. We presume that the prescribing practice in hospitals should be improve necessarily. The study proposes that there is the scope of development in prescribing practice to accomplish norms of rational prescribing. 


\section{ACKNOWLEDGEMENT}

We are grateful to Hon'ble vice chancellor, IFTM University for his constant encouragement, valuable insight and facilities at all stage of this work and also thankful of all the staff and patients of district Moradabad's hospitals for participating in the study.

\section{AUTHOR CONTRIBUTIONS}

AS and AA carried out the Study Design, Data Collection and also conducted the literature review. AS: the main author has also their role in drafting of the manuscript as well as coordination with other authors (MP, VR, AK\&NAK) of this study. MP makes their imperative role in analyzing and interpreting of the manuscript and also help in drafting. NAK has their crucial role in designing the work and also helps in rigorous interpretation of the result as a project supervisor. A part from the authors VR and AK also supports to collect the study data.

\section{ETHICAL APPROVAL}

This work does not require a written consent as no animals and human were used for in-vivo study. This study is the opinion based study.

\section{REFERENCES}

1. WHO policy perspectives on medicines promoting rational use of medicines: core components. Geneva: world health organization; 2002.

2. Bennett PN, Brown MJ. Inflammation, arthritis and non-steroidal anti-inflammatory drugs. In: Clinical pharmacology. 9th edition, New York: Churchill Living-stone, 2004, pp. 279-98.

3. Rahman MS, Begum $Z$ A, Samad MK. Prescribing pattern of non-steroidal antiinflammatory drugs at outpatient departments of teaching hospitals. Bangladesh J Pharmacol. 2007; 2:1-6.

4. Ong CK, Lirk P, Tan CH, Seymour RA. An evidence-based update on non-steroidal anti- inflammatory drugs .Clin Med Res. 2007; 5(1):19-34.

5. Ingle PV. Evaluation of symptomatic efficacy and safety of diclofenac versus etrocoxib in combination with serratiopeptidase in knee osteoarthritis. Genesis j pharm. 2014; 4:10-14.

6. Yuen YH, Chang S, Chong CK, Lee SC, Critchley JA, Chan JC. Drug utilization in a hospital general medical outpatient clinic with particular reference to antihypertensive and antidiabetic drugs. J Clin Pharm and Ther. 1998; 23:287-94.

7. WHO Action Programme on Essential Drugs and Vaccines. How to investigate drug use in health facilities: selected drug use indicators. Geneva, World Health Organization, 1993. Brian S. Phamacoepidemiology. 4 th ed. British library cataloguing in publication data. John wily and sons: 408.

8. Frolich JC. A classification of NSAIDs according to the relative inhibition of cyclooxygenase isoenzymes. Trends pharmacol sci. 1997; 18(1):30-4.

9. Alam K, Mishra P, Prabhu M, Shankar PR, Palaian S, Bhandari RB. A study on rational drug prescribing and dispensing in outpatients in a tertiary care tertiary care teaching hospital of westem Nepal. Kathmandu univ med J. 2006; 4(4):436-43.

10. Sharif S, Al-shaqra M, Hajjar H, Shamout A,Wess L. Patterns of drug prescribing in a hospital in dubai, united arab emirates. Libyan j med. 2008; 3(1):10-12.

11. Ingle PV, Aravadiya JP, Patil SD, Surana SJ. Efficacy of cefoperzone and sulbactam as a surgical antibiotic in hip surgery.Int J Pharma Bio Sci. 2011; 2(1):211-9.

12. Otoom S, Batieha A, Hadidi H, Hasan M, ALSaudi K. Evaluation of drug use in Jordan using WHO prescribing indicators. East Medi Health J. 2002; 8(4-5):537-43. 